\title{
Esophageal lesions in myeloproliferative neoplasms
}

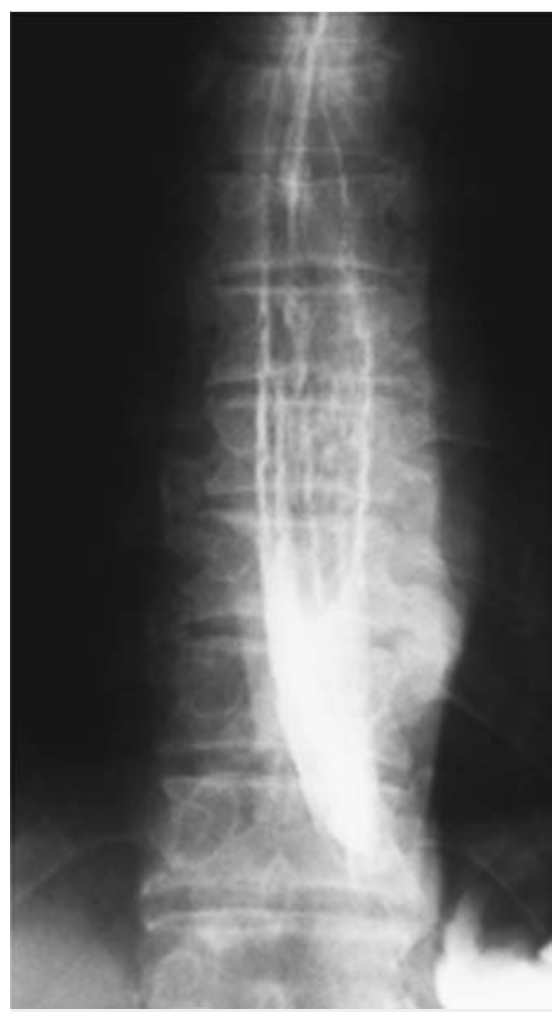

Fig. 1 Upper gastrointestinal barium study of a 67-year-old man with worsening odynophagia showing several longitudinal ulcers in the middle to lower esophagus.

A 67-year-old man was admitted to our hospital with worsening odynophagia. He had been diagnosed as having chronic neutrophilic leukemia based on excessive neutrophilia without blasts, anemia, hyperplastic bone marrow with normal neutrophilic maturation, and hepatosplenomegaly, without bcr/abl rearrangement [1]. Finally, he was rediagnosed as having myeloproliferative neoplasm (MPN), unclassifiable, according to the 2008 World Health Organization (WHO) classification [2]. In the 2 years after the diagnosis was made he was treated with hydroxyurea, interferon-alpha, Ara-C, and then VP-16. Laboratory studies revealed leukocytosis $\left(15.4 \times 10^{9} / \mathrm{L}, 69 \%\right.$ mature neutrophils) without blasts, anemia (hemoglobin $10.2 \mathrm{~g} / \mathrm{dL}$ ), and thrombocytosis $\left(569 \times 10^{9} / \mathrm{L}\right)$. Fluoroscopy revealed several longitudinal ulcers in the middle to lower esophagus ( Fig. 1). Esophagogastroduodenoscopy showed multiple longitudinal and aphthoid ulcers ( $\bullet$ Fig. 2).

There were not specific lesions in the stomach, duodenum, and colorectum.

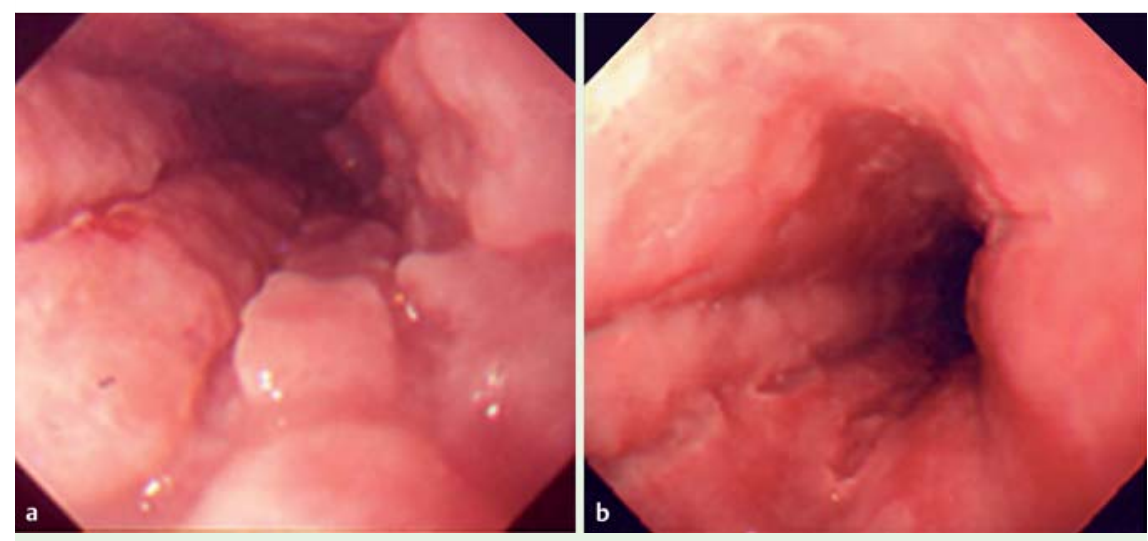

Fig.2 Esophagogastroduodenoscopy showed multiple (a) longitudinal and (b) aphthoid ulcers, but no surrounding redness, white coat, or raised plaques in relation to the ulcers.

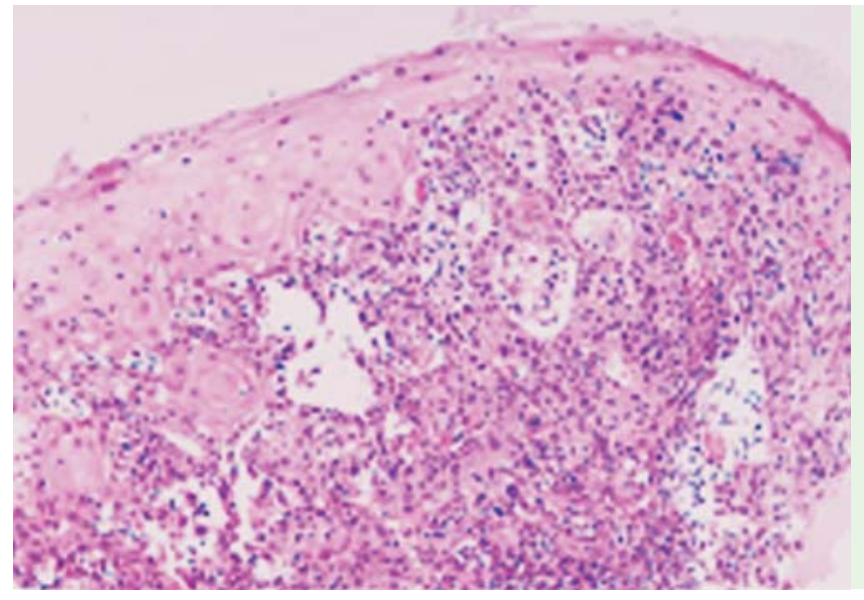

Fig. 3 Histological section (hematoxylin and eosin) showing intense infiltration of polymorphic neutrophils in the mucosa as well as the vascular wall. The biopsy specimen did not contain any microorganisms, inclusion bodies, gigantic cells, or granulomas.

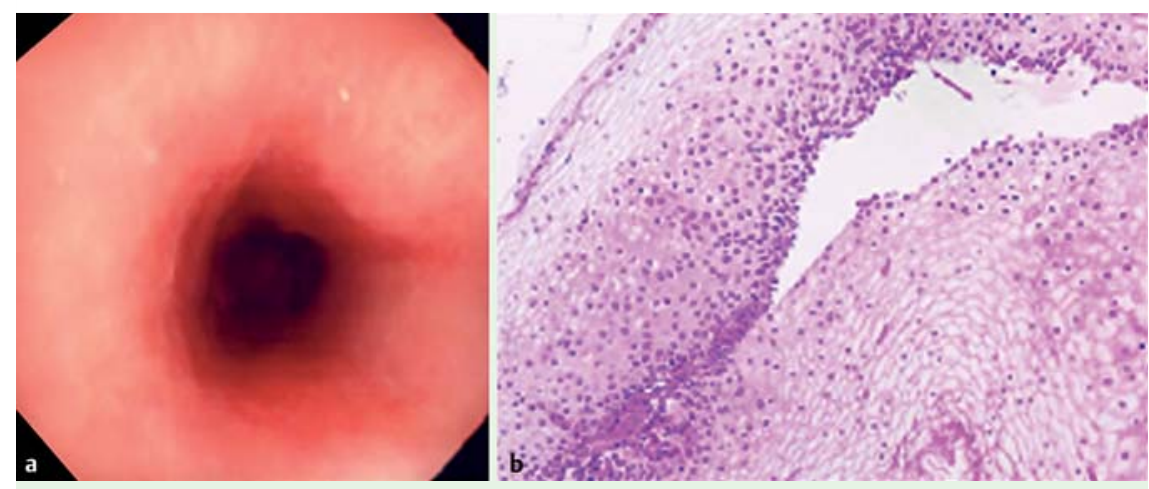

Fig. 4 Both the (a) endoscopic appearance and (b) histopathological picture were improved after chemotherapy.

Histological examination revealed an intense infiltration of polymorphic neutrophils (mimicking the neoplastic cells detected in the bone marrow) in the mucosa as well as the vascular wall ( $\bullet$ Fig.3), indicating neoplastic cell infiltration to esophagus. Prednisolone $20 \mathrm{mg}$ daily was prescribed in addition to VP-16, resulting in improvement of the esophageal lesions (๑ Fig.4).

Esophageal manifestations in leukemic patients include hemorrhagic lesions, leukemic infiltrates, and pseudomembranous and fungal esophagitis [3,4]. Although esophageal involvement was reported in $7.2 \%$ of 207 autopsied cases 
with leukemia, only a few cases have been diagnosed antemortem [5]. Endoscopically, the lesions include shallow circular ulcers and erosive esophagitis. In addition, the autopsy review reported that esophageal leukemia was related to a high initial leukocyte count and usually associated with leukemic infiltration into other soft tissue/organs. Odynophagia and dysphagia in patients with leukemia are possibly caused by chemotherapy toxicity, infection, reflux, and benign strictures, however, esophageal leukemic infiltration should also be considered. Besides the longitudinal and aphthoid ulcers present in our case, endoscopic appearances may vary depending on the characteristics of the infiltrating neoplastic cells.

Endoscopy_UCTN_Code_CCL_1AB_2AC_3AB

Competing interests: None

\section{T. Sawada', Y. Adachi', 2, Y. Ishii ${ }^{3}$, H. Yasui ${ }^{2}$, Y. Arimura ${ }^{2}$, T. Endo ${ }^{1}$}

${ }^{1}$ Division of Gastroenterology, Sapporo

Shirakaba-dai Hospital, Sapporo, Japan

2 First Department of Internal Medicine, Sapporo Medical University, Sapporo, Japan

${ }^{3}$ Division of Pathology, Sapporo

Shirakaba-dai Hospital, Sapporo, Japan

\section{References}

1 Yasui H, Adachi Y, Ishii Y et al. Mucormycosis as an etiology of cerebral hemorrhage in patients with chronic neutrophilic leukemia. Am J Med 2003; 115: 674-676

2 Tefferi A, Vardiman JW. Classification and diagnosis of myeloproliferative neoplasms: the 2008 World Health Organization criteria and point-of-care diagnostic algorithms. Leukemia 2008; 22: 14-22

3 Fulp SR, Nestok BR, Powell BL et al. Leukemic infiltration of the esophagus. Cancer 1993; 71: $112-116$

4 Ebert E, Hagspiel KD. Gastrointestinal manifestations of leukemia. J Gastroenterol Hepatol 2012; 46 (1): 25 - 30

5 Prolla JC, Kirsner JB. The gastrointestinal lesions and complications of leukemias. Ann Intern Med 1964; 61: 1084-1103
Bibliography

DoI http://dx.doi.org/ 10.1055/s-0031-1291754 Endoscopy 2012; 44: E173-E174

(c) Georg Thieme Verlag KG

Stuttgart · New York

ISSN 0013-726X

Corresponding author

\section{Y. Adachi}

Division of Gastroenterology

Sapporo Shirakaba-dai Hospital

2-18 Tsukisamu-Higashi

Toyohira-Ku

Sapporo 062-0052

Japan

Fax: +81-11-852-8194

yadachi@sapmed.ac.jp 